\title{
Hydration Properties of Cement Pastes with Al-Zinc Oxide and Zinc Oxide Nanoparticles
}

\author{
SeyedAli Ghahari, ${ }^{1}$ Ehsan Ghafari, ${ }^{1}$ Pengkun $\mathrm{Hou}^{4}$ and $\mathrm{Na} \mathrm{Lu}{ }^{1,2,3^{*}}$
}

The current study aims to evaluate the influence of aluminum $\mathrm{ZnO}$ (AZO) alloys and undoped zinc oxide ( $\mathrm{ZnO}$ ) nanoparticles on hydration behavior of cement paste composites. The study indicated that the addition of AZO nanoparticles resulted in a decrease in the induction period time compared to the addition of $\mathrm{ZnO}$ nanoparticles. The effect can be attributed to the aluminum acceleration shields effect, since AZO nanoparticles contain four and five fold coordinated aluminum sites and each of Al site coordinated to six oxygen atoms, the pastes containing AZO exhibited more hydration.

Keywords: $\mathrm{ZnO}$ nanoparticles; Cement Composite Materials; Hydration behavior

Received 11 July 2018, Accepted 29 November 2018

DOI: $10.30919 / \mathrm{esmm} 5 \mathrm{f} 172$

\section{Introduction}

Using nanomaterials for civil infrastructure applications has rapidly increased in recent years. ${ }^{1-8}$ Nanoparticles can improve the mechanical properties and durability of cement and concrete composites. By using particles that are smaller than cement particles, denser particle packing and consolidation would be attainable, ${ }^{9-14} \mathrm{ZnO}$ is one of the most common nanoparticles used as cement additives due to its unique properties including self-cleaning and pollution remediation, ${ }^{15,16} \mathrm{UV}$ blocking characteristics, ${ }^{17,18}$ gas sensing, ${ }^{19}$ and energy harvesting ${ }^{20}$ for structures and environment. Furthermore, $\mathrm{ZnO}$ has piezoelectric characteristic as it is in a non-centrosymmetric crystallographic phase, ${ }^{21,22}$ therefore, it is a promising technology to be used in structural health monitoring applications.

One of the key issues of using $\mathrm{ZnO}$ in cement and concrete is its influences on the hydration properties. In cement and concrete industry, $\mathrm{ZnO}$ has been used as admixture for cement paste and concrete mixture to tailor intrinsic properties of the composite by taking advantage of its superfine particle size feature, however, retardation on cement hydration is one of the major drawbacks of using $\mathrm{ZnO}$ in cement and concrete, especially when setting time should not be elongated. 23,29-31 Study performed by Puertas et al. investigated the hydration and leaching behavior of cement mixed with $\mathrm{ZnO}$. It was shown that adding $\mathrm{ZnO}$ to the cement paste could significantly prolong the initial and final setting times $^{25}$ Researchers have also studied the effect of zinc ions on the hydration properties of cement paste with supplementary cementitious materials (SCM) ${ }^{26,27}$ It showed that the chemical retardation effect of $\mathrm{Zn}$

${ }^{1}$ Lyles School of Civil Engineering, Sustainable Materials and Renewable Technology (SMART) Lab, Purdue University, USA

${ }^{2}$ School of Materials Engineering, Purdue University, USA

${ }^{3}$ Birck Nanotechnology Center, Purdue University, USA

${ }^{4}$ Shandong Provincial Key Lab for the Preparation and Measurement of Building Materials, Jinan, Shandong, 250022, China

*E-mail: luna@purdue.edu
(II) could be eliminated in metakaolin-cement mixtures, and the modification of the physichemical property of metakaolin during calcination could be the reason, which resulted in the acceleration of the mixture. $^{28}$

The modification of the physichemical property of the SCM sheds lights on the potential possibility of using physichemical-modified $\mathrm{Zn}$ to tune the hydration properties of cement. In this study, we have investigated the effect of binary alloys of $\mathrm{ZnO}$ nanoparticles additives on hydration behavior of cement paste. This study was designed to systematically investigate the hydration process of cement mixtures reinforced with $\mathrm{ZnO}$ and aluminum $\mathrm{ZnO}$ alloys (AZO) nanoparticles and their related physical and chemical properties. Samples with 0.2, $0.4,0.6,0.8,1$ wt.\%. $\mathrm{ZnO}$ and $\mathrm{AZO}$ nanoparticles were prepared and the effect of chemical properties on the hydration behavior of the pastes was examined. X-ray diffractometry (XRD), differential scanning calorimetry (DSC), thermogravimetry analysis (TGA), and fouriertransform infrared (FTIR) spectrometry were performed on the samples in order to elucidate the chemical aspects of the hydration properties. As such, the result of this study can enhance fundamental understanding of $\mathrm{ZnO}$ and $\mathrm{AZO}$ on hydration behavior of cement.

\section{Experimental section}

All specimens were cast with a Twister Evolution vacuum mixer, and cured with potable water and Portland cement (C) type I 42.5R according to ASTM C150. ${ }^{32}$ For maintaining a comparable workability, a polycarboxylate ether based superplasticizer (SP) with a density of $1.108 \mathrm{~g} / \mathrm{cm}^{3}$ was used. As admixture, dry $\mathrm{ZnO}$ and aluminum $\mathrm{ZnO}$ alloys (AZO) were added to the mixture. The physical and chemical characteristics of cement, $\mathrm{ZnO}$ and AZO powders are presented in Table 1 and Table 2, respectively. Table 3 presents eleven series of mixtures, prepared with $\mathrm{ZnO}, \mathrm{AZO}$, and a reference mixture without nanoparticles additives. Nanoparticles were incorporated as cement replacement by $0.2,0.4,0.6,0.8$, and 1 of weight fractions (wt. \%) of cement. The total content of the powder including cement and nanoparticles was kept constant in volume. In addition, the water to binder ratio was kept constant at 0.4 for all the mixtures. At the ages of 3, 7, and 28 days, 
Table 1 Chemical composition and physical properties of cement.

\begin{tabular}{cc}
\hline Chemical Analysis & Cement (wt. \%) \\
$\mathrm{SiO}_{2}$ & 20.9 \\
$\mathrm{Al}_{2} \mathrm{O}_{3}$ & 4.60 \\
$\mathrm{Fe}_{2} \mathrm{O}_{3}$ & 3.15 \\
$\mathrm{CaO}$ & 62.0 \\
$\mathrm{MgO}$ & 2.00 \\
$\mathrm{SO}_{3}$ & 3.60 \\
$\mathrm{~K}_{2} \mathrm{O}$ & $<1$ \\
$\mathrm{Na}_{2} \mathrm{O}$ & 3.14 \\
$\mathrm{Specific} \mathrm{gravity}$ & $<1$ \\
\hline
\end{tabular}

sample were ground and 100 mesh size powder were mixed with ethanol then heated in a vacuum oven for $24 \mathrm{~h}$ at $60{ }^{\circ} \mathrm{C}$ to stop the hydration process.

In order to study the hydration properties of cement paste, the heat flow rate and cumulative heat release were measured with a TAM Air isothermal calorimeter according to ASTM C1702. ${ }^{33}$ The temperature was maintained at $23 \pm 0.1{ }^{\circ} \mathrm{C}$ during the test. Before starting data acquisition, TAM was set for $30 \mathrm{~min}$ to stabilize the baseline. After 10 min from mixing, the cement paste was poured into specific ampoules. The sealed ampoules were then inserted into the TAM chamber and the device started to measure the temperature after reaching the equilibration.

Characterization of phase and crystalline composition were performed by XRD, TGA, and FTIR. The samples were prepared as a power form for XRD analysis with Siemens D500 and thermal gravimetric analysis with TGA Quantachrome Q50. The powder was situated in $\mathrm{Cu}$ ko radiation and $\mathrm{Ni}$ filler with $50 \mathrm{kV}$ and $30 \mathrm{~mA}$ working condition for $4-75^{\circ}(2 \theta)$ range analyzing with step size of $0.02^{\circ}$. Jade software was used for analyzing the results. DSC was performed with TA Instruments DSC 2010 to approve the accuracy of TGA results. Samples were tested in titanium cylinder under a nitrogen gas with a scanning rate of $10{ }^{\circ} \mathrm{C} / \mathrm{min}$ from $25^{\circ} \mathrm{C}$ to $1000{ }^{\circ} \mathrm{C}$. FTIR with Thermo Nicolet Nexus FTIR was used with the ability of quantifying the chemical compositions in the range of $4000-800 \mathrm{~cm}^{-1}$. Ten times scan with a resolution of $2.5 \mathrm{~cm}^{-1}$ was performed during the FTIR analysis. The phase characterization was performed using OMNIC software. In

Table 2 Properties of $\mathrm{ZnO}$ nanoparticles.

\begin{tabular}{ccccccc}
\hline Formula & Aluminum content & $\begin{array}{c}\text { Specific Surface } \\
\text { area }\left(\mathrm{m}^{2} / \mathrm{g}\right)\end{array}$ & Purity & Crystal Phase & $\begin{array}{c}\text { Mean } \\
\text { Diameter(nm) }\end{array}$ & $\begin{array}{c}\text { Density } \\
\left(\mathrm{g} / \mathrm{cm}^{3}\right)\end{array}$ \\
\hline $\mathrm{ZnO}$ & 0 & $54 \pm 20$ & $>99.9$ (wt. \%) & Zincite (hexagonal) & $20 \pm 5$ & 5.6 \\
$\mathrm{AZO}$ & 0.2 (wt. \%) & $54 \pm 20$ & $>99.9$ (wt. \%) & Zincite (hexagonal) & $20 \pm 5$ & 5.6 \\
\hline
\end{tabular}

Table 3 Composition of pastes mixture (by weight, $\mathrm{g} / \mathrm{cm}^{3}$ ).

\begin{tabular}{ccccccc}
\hline \multirow{2}{*}{ Ref } & & Cement & Water & SP & ZnO & AZO \\
& PC & 593.9 & 207.9 & 2.4 & 0 & 0 \\
& ZnO_0.2 & 592.7 & 207.9 & 2.4 & 1.18 & 0 \\
\multirow{2}{*}{ ZnO } & ZnO_0.4 & 591.5 & 207.9 & 2.4 & 2.37 & 0 \\
Mixtures & ZnO_0.6 & 590.3 & 207.9 & 2.4 & 3.56 & 0 \\
& ZnO_0.8 & 589.1 & 207.9 & 2.4 & 4.75 & 0 \\
& ZnO_1 & 587.9 & 207.9 & 2.4 & 5.93 & 0 \\
& AZO_0.2 & 592.7 & 207.9 & 2.4 & 0 & 1.18 \\
\multirow{2}{*}{ AZO } & AZO_0.4 & 591.5 & 207.9 & 2.4 & 0 & 2.37 \\
& AZO_0.6 & 590.3 & 207.9 & 2.4 & 0 & 3.56 \\
& AZO_0.8 & 589.1 & 207.9 & 2.4 & 0 & 4.75 \\
& AZO_1 & 587.9 & 207.9 & 2.4 & 0 & 5.93 \\
\hline
\end{tabular}


order to stop the hydration reactions, the samples were stored in acetone bottle for $24 \mathrm{~h}$ before dried in $60{ }^{\circ} \mathrm{C}$ oven.

\section{Results and discussions}

\subsection{Hydration analysis}

The rate of heat evolution, normalized by the mass of cementitious material (cement and $\mathrm{ZnO}$ nanoparticles), as a function of time for paste mixtures containing different dosage of $\mathrm{ZnO}$ is shown in Fig. 1. As shown, the addition of $\mathrm{ZnO}$ and $\mathrm{AZO}$ to the reference sample led to a significant delay in the induction period. The analyzed data including the maximum peak, time to maximum peak, and induction period are presented in Table 4. The samples with elongated induction stage had a delay reaching to hydration peak, leading to a significant lower cumulative heat. The results indicated that the addition of 1 wt. $\% \mathrm{ZnO}$ and AZO delayed the hydration up to $110 \mathrm{~h}$ and $108 \mathrm{~h}$, respectively. The retardation effect can be attributed to the delay in the formation of $\mathrm{C}-\mathrm{S}-\mathrm{H}$ on the surface of $\mathrm{C}_{3} \mathrm{~S}$ in hydration reaction. ${ }^{34-38}$ Zinc hydroxide is the product of the reaction between $\mathrm{ZnO}$ and water, which has been proven to provide a circumference around the calcium silicate hydrate (C-S-H) layer so that the $\mathrm{C}_{3} \mathrm{~S}$ and $\mathrm{C}_{2} \mathrm{~S}$ hydration were retarded. ${ }^{34,37}$ Although the $\mathrm{Zn}(\mathrm{OH})_{2}$ and $\mathrm{CaZn}_{2}(\mathrm{OH})_{6} \cdot 2 \mathrm{H}_{2} \mathrm{O}$ cannot be detected by $\mathrm{XRD}$, the corroboration of the existence of $\mathrm{Zn}(\mathrm{OH})^{3-}, \mathrm{Zn}(\mathrm{OH})_{4}^{-2}$ and/or $\mathrm{CaZn}_{2}(\mathrm{OH})_{6} \cdot 2 \mathrm{H}_{2} \mathrm{O}$ was confirmed by FTIR technique which is discussed further in this manuscript.

$$
\left.\mathrm{Zn}(\mathrm{OH})_{4}^{2-}+\mathrm{Ca}^{2+}+\mathrm{H}_{2} \mathrm{O} \rightarrow \mathrm{Ca} \mathrm{Zn}(\mathrm{OH})_{3}\right)_{2} \cdot 2 \mathrm{H}_{2} \mathrm{O}+2 \mathrm{OH}^{-}
$$

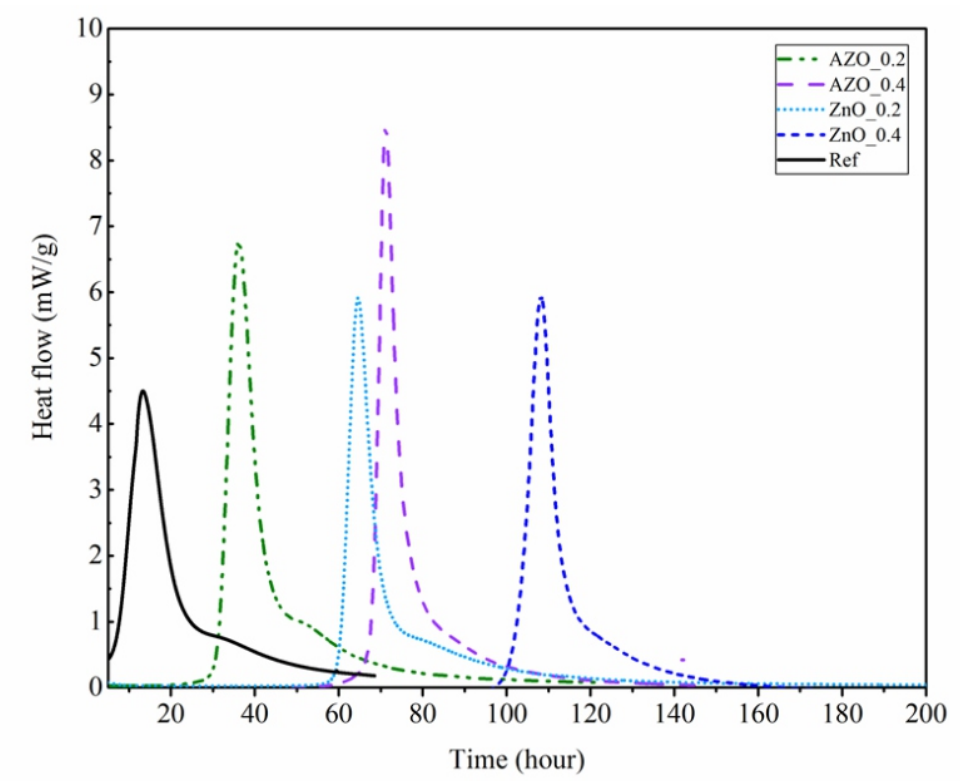

Fig. 1 Heat flow of cement paste containing AZO and $\mathrm{ZnO}$.

Table 4 The obtained hydration parameters from isothermal calorimetry.

\begin{tabular}{cccc}
\hline \multicolumn{2}{c}{ Sample } & $\begin{array}{c}\text { End of induction } \\
\text { period (hour) }\end{array}$ & $\begin{array}{c}\text { Time to maximum exothermic peak } \\
\text { (hour) }\end{array}$ \\
\hline \multirow{2}{*}{ Ref } & PC & 5 & 13.3 \\
& ZnO_0.2 & 58 & 64.5 \\
Mixtures & ZnO_0.4 & 98 & 108.3 \\
& ZnO_0.6 & 98 & 110.1 \\
& ZnO_0.8 & 100 & 104.1 \\
& ZnO_1 & 102 & 110.61 \\
AZO & AZO_0.2 & 25 & 36.2 \\
& AZO_0.4 & 60 & 71.2 \\
& AZO_0.6 & 82 & 96.2 \\
& AZO_0.8 & 94 & 106.2 \\
& AZO_1 & 92 & 108.3 \\
\hline
\end{tabular}


Moreover, the results indicated that the induction period can be reduced significantly by adding AZO_0.2 and AZO_0.4 as compared to $\mathrm{ZnO} 0.2$ and $\mathrm{ZnO} 0.4$ mixtures. As presented in Table 4, AZO_0.2 and AZO_0.4 pastes exhibited roughly a $36 \mathrm{~h}$ and $51 \mathrm{~h}$ delay in the retardation time to reach the peak comparing to the reference, which is $43 \%$ and $35 \%$ lower than the retardation period of $\mathrm{ZnO}_{-} 0.2$ and $\mathrm{ZnO} 0.4$ samples. This implies that the higher Al alloy content of $\mathrm{AlZnO}$ would lead to a significant change in the early hydration of cement particles and eliminate the retardation effect of $\mathrm{ZnO}$.

\subsection{XRD}

Calcium silicate hydrate (C-S-H), calcium hydroxide $(\mathrm{CH})$, and ettringite phase change and transformation analysis were performed on all mixtures at the ages of 3 and 28 days. The results of XRD analysis are presented in Fig. 2 and Fig. 3. AZO_1 showed a significant amount of unhydrated cement particles at the age of 3 days. Strong change in peak intensities can be seen between $\mathrm{PC}$ and $\mathrm{ZnO}$ and AZO. As Fig. 2 shows at 3 days hkl 001 and $012(\mathrm{CH})$ is mostly noticeable for PC at $18.5^{\circ}(2 \theta)$. However, for $\mathrm{ZnO} \_1$ and $\mathrm{AZO}$ _1, no significant amount of $\mathrm{CH}$ was recognized. This is an indication of delay in hydration at high dosage of $\mathrm{ZnO}$ and $\mathrm{AZO}$ nanoparticles. Main products of hydration of $\mathrm{C}_{3} \mathrm{~S}$ and $\mathrm{C}_{2} \mathrm{~S}$ are $\mathrm{C}-\mathrm{S}-\mathrm{H}$ and calcium hydroxide $\left(\mathrm{Ca}(\mathrm{OH})_{2}\right)$ which are produced according to the following exothermic reactions:

$$
\begin{aligned}
& 2 \mathrm{C}_{3} \mathrm{~S}+6 \mathrm{H} \rightarrow \mathrm{C}_{3} \mathrm{~S}_{2} \mathrm{H}_{3}+3 \mathrm{Ca}(\mathrm{OH})_{2} \\
& 2 \mathrm{C}_{2} \mathrm{~S}+4 \mathrm{H} \rightarrow \mathrm{C}_{3} \mathrm{~S}_{2} \mathrm{H}_{3}+\mathrm{Ca}(\mathrm{OH})_{2}
\end{aligned}
$$

ZnO 0.4 and AZO 0.4 both had a similar amount of $\mathrm{CH}$ at 3 days, slightly lower than that of the Portland Cement (PC). PC had significant lower amount of $\mathrm{C}_{3} \mathrm{~S}$ (hkl 204 and 009) and $\mathrm{C}_{2} \mathrm{~S}$ (hkl 116, 020) comparing to samples with $\mathrm{ZnO}$ or $\mathrm{AZO}$.

Compared to the results obtained at 3 days, XRD analysis for the specimens at 28 days showed a higher amount of calcium hydroxide (CH) for PC, ZnO_0.4, and AZO_0.4. The selected results are presented in Fig. 3. At $18.5^{\circ}$ and $34^{\circ}(2 \theta)$ a considerable decrease in the peaks that are related to the less availability of $\mathrm{C}_{2} \mathrm{~S}$ and $\mathrm{C}_{3} \mathrm{~S}$, and a comparative increase in the peaks of $\mathrm{CH}$ is observable. However, $\mathrm{ZnO}_{-} 1$ and AZO_1 still show a significant amount of un-hydrated cement, i.e. high amount of $\mathrm{C}_{2} \mathrm{~S}$ and $\mathrm{C}_{3} \mathrm{~S}$. The peak of hkl $001(\mathrm{CH})$ for $\mathrm{ZnO} 0.4$ was comparatively lower than that of AZO_0.4. It was observed that the amount of $\mathrm{C}_{2} \mathrm{~S}$ and $\mathrm{C}_{3} \mathrm{~S}$ for $\mathrm{ZnO}_{-} 0.4$ were higher than that of the amount of $\mathrm{C}_{2} \mathrm{~S}$ and $\mathrm{C}_{3} \mathrm{~S}$ for AZO_0.4. The amount of $\mathrm{C}_{3} \mathrm{~S}$ (hkl 204 and 009) and $\mathrm{C}_{2} \mathrm{~S}$ (hkl 116, 020) was lower for PC compared to that of $\mathrm{ZnO} 1$ and $\mathrm{AZO}$ 1. The results imply that the higher Al alloy content in $\mathrm{ZnO}$ would change the hydration of cement particles. AZO_0.2 and AZO_0.4 showed higher amount of $\mathrm{CH}$ at the age of 28 days compared to that of $\mathrm{ZnO}_{-} 0.2$ and $\mathrm{ZnO} \_0.4$, respectively.

\subsection{DSC/TGA}

The evaporation of chemical groups in different mixtures were determined by DSC and TGA using TA Instruments DSC 2010 and Quantachrome Q50, respectively. Fig. 4 and 5 shows the TGA curve and heat flow curve for $\mathrm{ZnO} 0.4$ and $\mathrm{AZO} 0.4$ at the age of 28 days, respectively. The results indicated the phase change in the following order: At $105{ }^{\circ} \mathrm{C}$ the mass loss is related to evaporable water, followed by an endothermic peak related to the thermogravimetric mass loss at 400-600 ${ }^{\circ} \mathrm{C}$. This step is associated with the decomposition of the available structural groups. And finally, an exothermic peak regarding the regeneration of new structural groups at $800-1000{ }^{\circ} \mathrm{C}$ is available. With higher amount of $\mathrm{ZnO}$ and $\mathrm{AZO}$, the endothermic peak area decreased. Subsequently, the peak of the endothermic curve happened at higher temperature. The peak area, presented in Table 5, was calculated with TA Instrument Universal Analysis 2000 software over a standard time range. A linear baseline was implemented for the calculations. No significant change was noticed between the reference sample and the samples containing $\mathrm{ZnO} 0.2$ and $\mathrm{AZO} \_0.4$ at 28 days, which indicates the fact that at lower dosages, such as $\mathrm{ZnO}_{-} 0.2$ and $\mathrm{AZO} 0.4$ nanoparticles could interchangeably be used in the cement mixture in a long run.

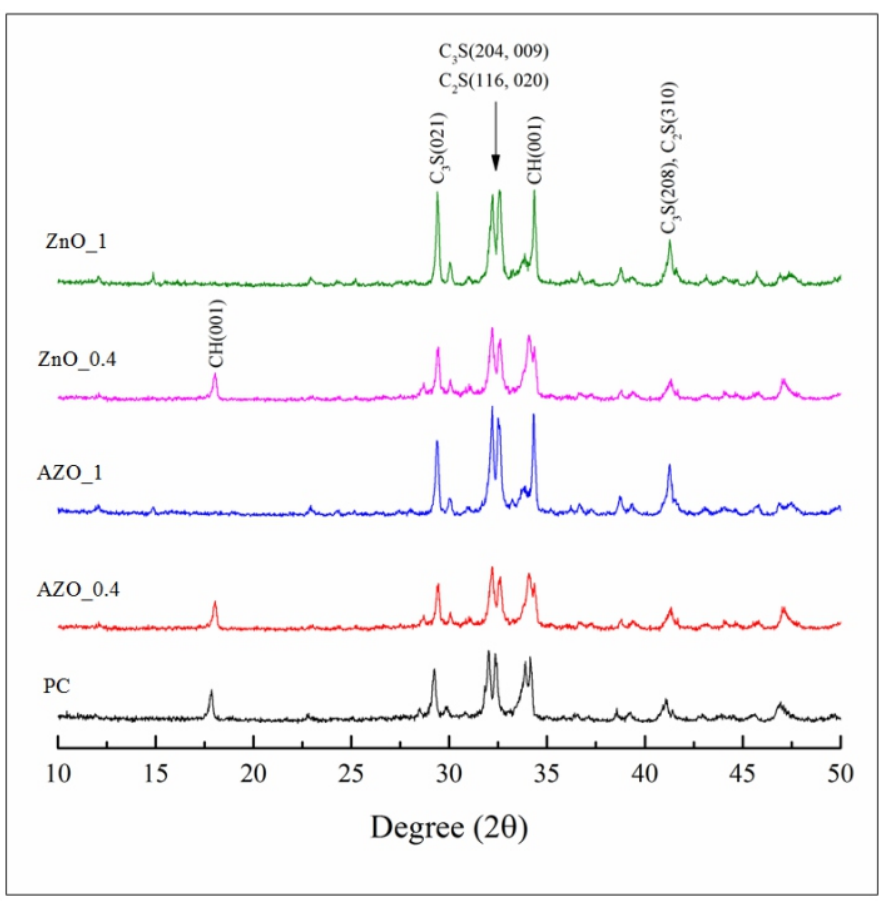

Fig. $2 \mathrm{XRD}$ analysis of paste mixtures containing $\mathrm{ZnO}$ and $\mathrm{AZO}$ at 3 days.

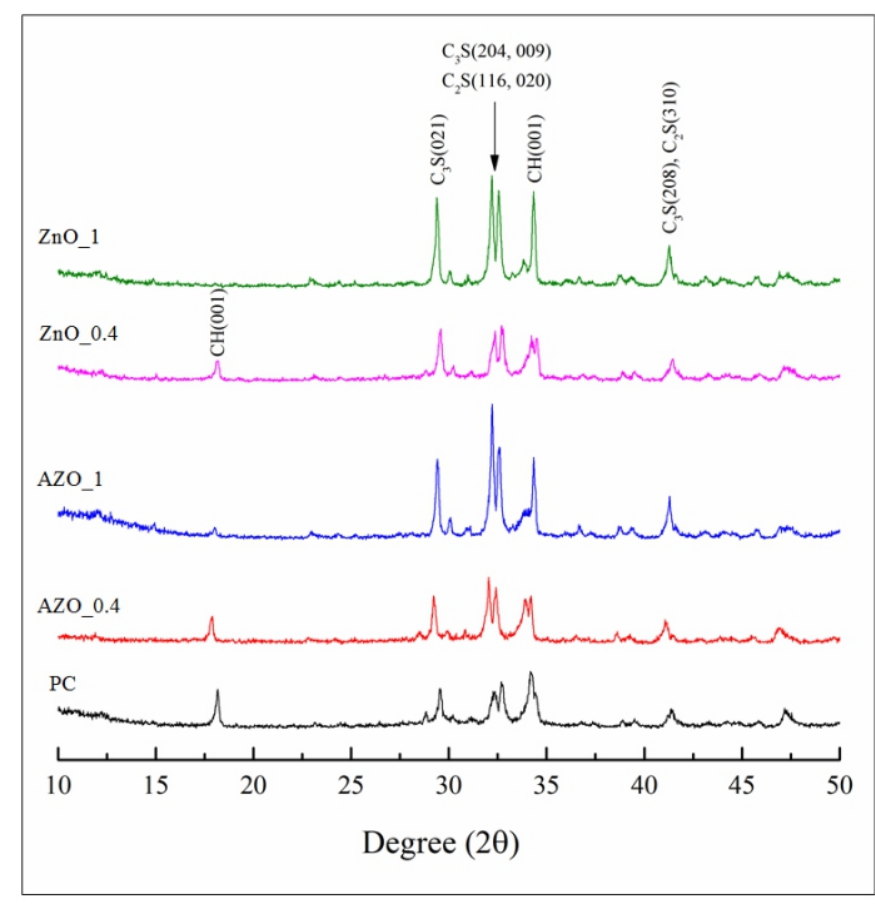

Fig. $3 \mathrm{XRD}$ analysis of paste mixtures containing $\mathrm{ZnO}$ and $\mathrm{AZO}$ at 28 days. 
Mass loss of water is attributed to the cement hydration reactions. The mass losses of cement paste for all specimens were obtained by thermal gravimetric analysis and the corresponding degree of hydration is presented in Fig. 6.

Mass loss of water due to humidity and dehydration of the hydration products during heating, is the first level which happens at $30-350{ }^{\circ} \mathrm{C}$. From the DSC analysis, at $190{ }^{\circ} \mathrm{C}, \mathrm{Zn}(\mathrm{OH})_{2}$ is dehydrated along with other hydration products. The second level of mass loss is attributed to dehydroxylation of $\mathrm{CH}$ products. This level happens at 350-530 ${ }^{\circ} \mathrm{C}$. The next level of mass loss is associated with the decarbonation of calcium carbonate at $530-750{ }^{\circ} \mathrm{C}$, and other products can be categorized at $750-1000{ }^{\circ} \mathrm{C}$. Rough estimation of $\mathrm{DOH}$ can be obtained by calculating the difference between the upper part of the TGA curve and the bottom part. $\mathrm{ZnO}$ mixes showed a decrease in the amount of the mass loss comparing to the control sample. High amount of $\mathrm{ZnO}$ nanoparticles, instead, increased the overall mass loss from 9.83 $\%$ to $11.65 \%$. This value for AZO samples was calculated 14 to $17 \%$ higher than that of the $\mathrm{ZnO}$ samples, meaning the latter retards cement hydration comparing to AZO. This can be attributed to the nucleation and growth poisoning of $\mathrm{C}-\mathrm{S}-\mathrm{H}$ caused by $\mathrm{ZnO}$ nanoparticles detailed as follows. ${ }^{29}$ The molecular structure of cement particles and hexagonal wurtzite structure of $\mathrm{ZnO}$ nanaoparticles are illustrated in Fig. 7. As

Table 5 Samples endothermic peak $(\mathrm{W} / \mathrm{g})$ and related Area $(\mathrm{J} / \mathrm{g})$.

\begin{tabular}{|c|c|c|c|c|c|c|c|c|c|c|c|}
\hline \multicolumn{12}{|l|}{7 days } \\
\hline \multirow{3}{*}{ DSC } & \multicolumn{10}{|c|}{ Mixture } & \multirow[b]{3}{*}{1} \\
\hline & \multicolumn{7}{|c|}{ AZO wt. \% } & \multicolumn{3}{|c|}{$\mathrm{ZnO}$ wt. \% } & \\
\hline & $\mathrm{PC}$ & 0.2 & 0.4 & 0.6 & 0.8 & 1 & 0.2 & 0.4 & 0.6 & 0.8 & \\
\hline $\begin{array}{l}\text { Endothermic } \\
\text { peak (W/g) }\end{array}$ & -0.70 & -0.68 & -0.55 & -0.51 & -0.47 & -0.13 & -0.58 & -0.30 & -0.27 & -0.16 & -0.12 \\
\hline Area $(\mathrm{J} / \mathrm{g})$ & 14.55 & 11.27 & 8.60 & 7.36 & 6.05 & 0.29 & 11.24 & 7.59 & 7.31 & 0.35 & 0.09 \\
\hline \multicolumn{12}{|l|}{28 days } \\
\hline \multicolumn{12}{|c|}{ Mixture } \\
\hline \multirow[t]{2}{*}{ DSC } & \multicolumn{7}{|c|}{ AZO wt. \% } & \multicolumn{3}{|c|}{$\mathrm{ZnO}$ wt. \% } & \\
\hline & $\mathrm{PC}$ & 0.2 & 0.4 & 0.6 & 0.8 & 1 & 0.2 & 0.4 & 0.6 & 0.8 & 1 \\
\hline $\begin{array}{l}\text { Endothermic } \\
\text { peak (W/g) }\end{array}$ & -0.79 & -0.73 & -0.59 & -0.55 & -0.52 & -0.18 & -0.59 & -0.42 & -0.31 & -0.25 & -0.16 \\
\hline Area $(\mathrm{J} / \mathrm{g})$ & 17.11 & 14.75 & 10.37 & 9.02 & 8.72 & 0.41 & 9.31 & 8.81 & 7.80 & 1.08 & 0.12 \\
\hline
\end{tabular}

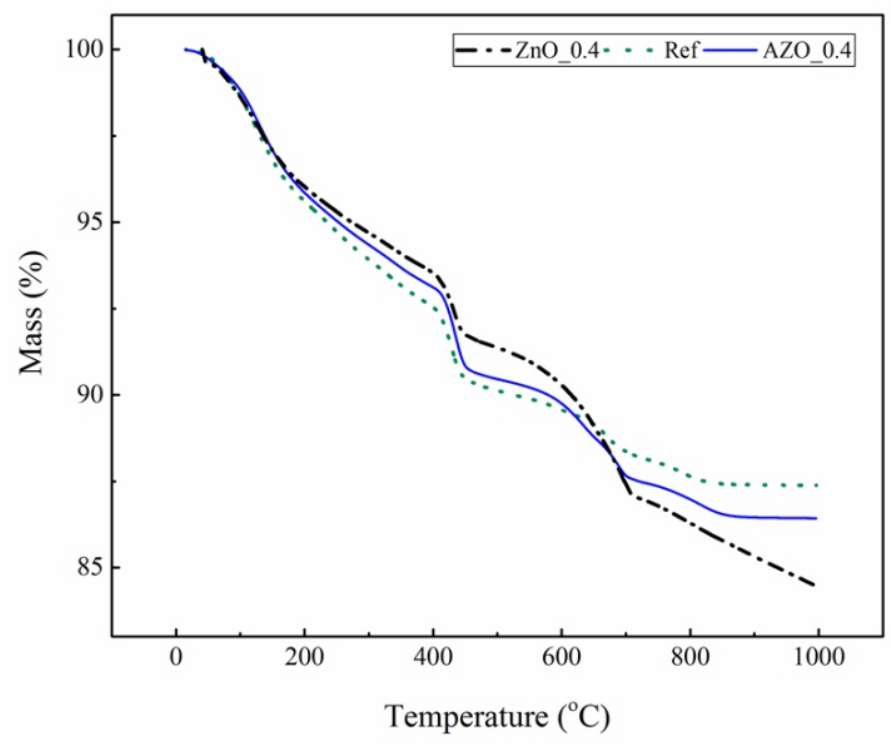

Fig. 4 TGA for 0.4 wt. \% $\mathrm{ZnO}$ and $\mathrm{AZO}$ at the age of 28 days.

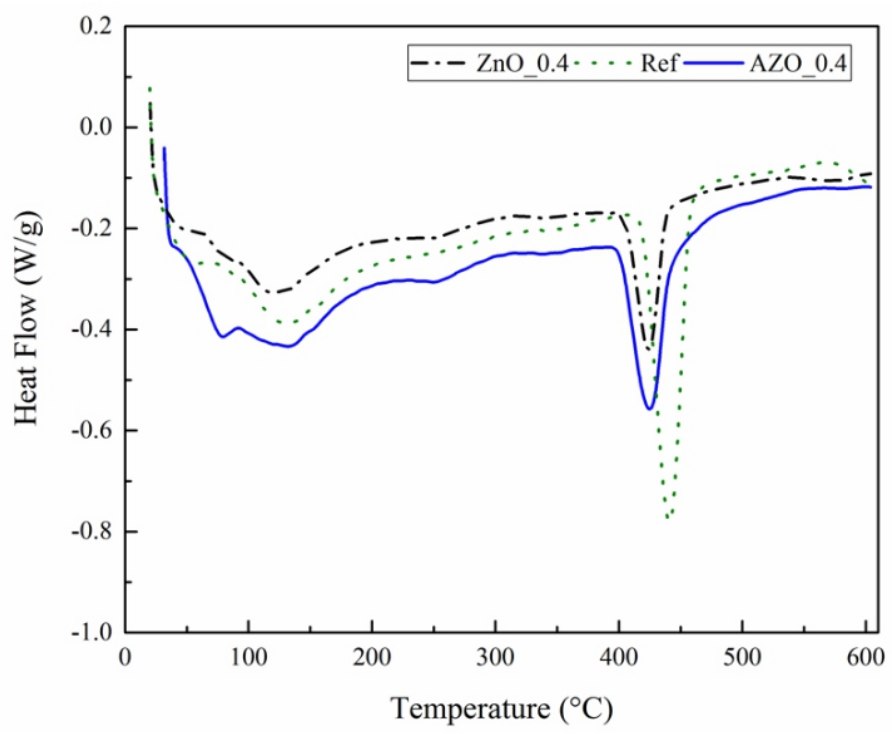

Fig. 5 DSC for 0.4 wt. \% $\mathrm{ZnO}$ and AZO at the age of 28 days. 


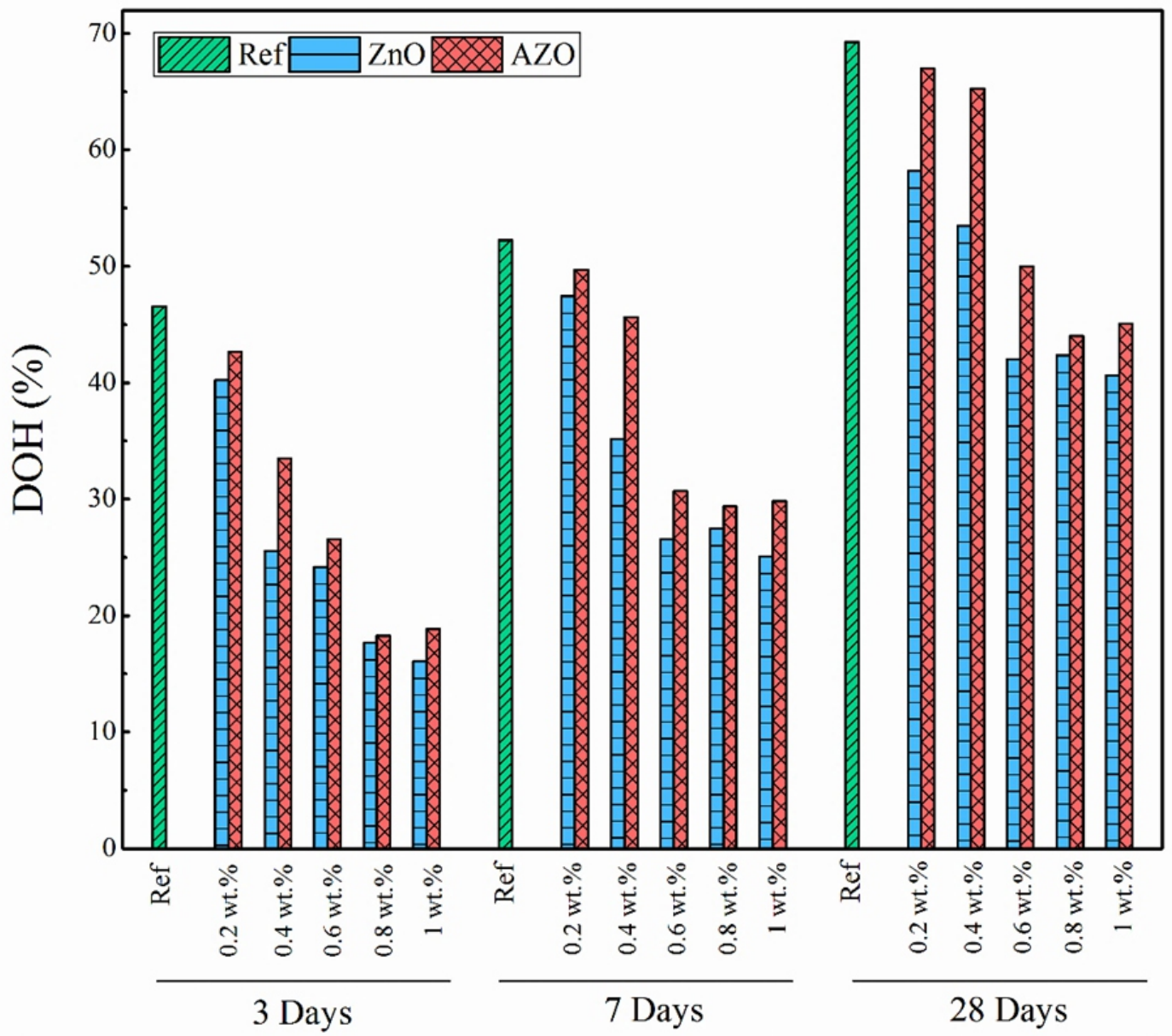

Fig. 6 Degree of hydration for all specimens.

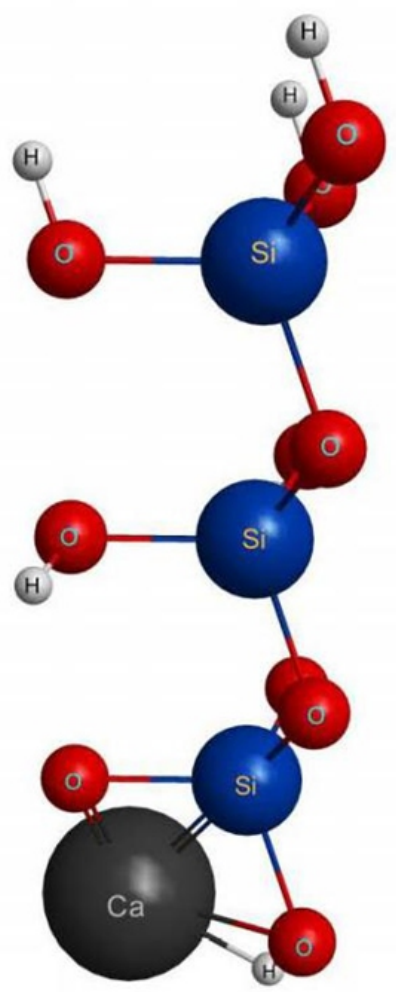

(a)

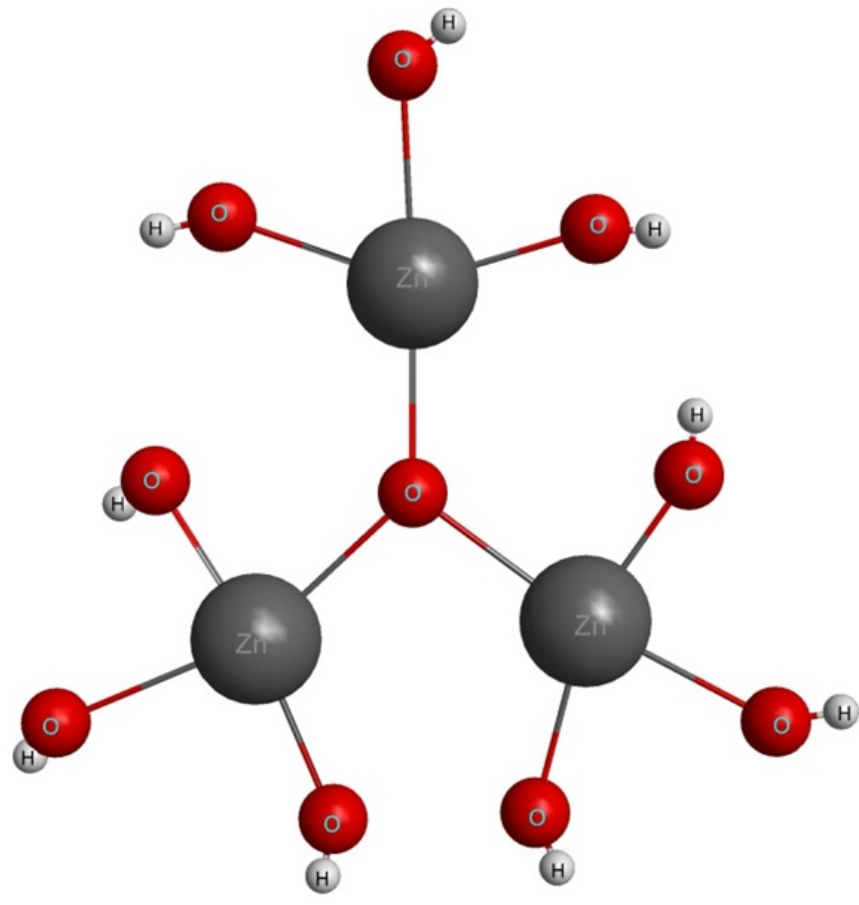

Fig. 7 Molecule structure of cement particle (a) and hexagonal wurtzite structure of $\mathrm{ZnO}$ nanoparticle (b) 
shown, $\mathrm{ZnO}$ has a wurtzite (B4) crystal structure - hexagonal cell with two lattice parameters which forms closed packed (hcp) sublattices. $\mathrm{ZnO}$ has tetrahedral coordination and it illustrates sp3 covalent-bonding. ${ }^{39}$ $\mathrm{Zn}-\mathrm{O}$ has bond dissociation energy of $284.1 \mathrm{~kJ} / \mathrm{mol}$ and this value for $\mathrm{Si}-\mathrm{O}$ is $798 \mathrm{~kJ} / \mathrm{mol}$. When exposed to C-S-H, ZnO nanoparticles' covalent-bonding are weakened due to the higher attraction forces from silicon and calcium chain molecules. Therefore, it can provide higher number of locations for nucleation sites for cement particles. According to a recent study performed by Avadhut et al., four and five-fold coordinated aluminum sites and an $\mathrm{Al}$ site coordinated to six oxygen atoms surround $\mathrm{ZnO}$ nanoparticles. Non-conductive phases that are heavily disordered are available around $\mathrm{ZnO}$ nanoparticles. ${ }^{40}$

It is reported that aluminum accelerates the hydration process of cement composite by densification of the interfacial transition zone (ITZ) which leads to the formation of larger crystal of portlandite. ${ }^{41.43}$ While no portlandite consumption is reported, C-S-H gel and $\mathrm{Ca}(\mathrm{OH})_{2}$ have been proven to be formed in the presence of alumina. When AZO nanoparticles are mixed with cement particles, aluminum will first react with the cement particles, and then $\mathrm{ZnO}$ nanoparticles will prohibit the hydration to occur. Therefore, adding $\mathrm{Al}$ to $\mathrm{ZnO}$ can act as an acceleration shields and could improve the hydration properties as expected. DSC data is in agreement with the calorimetry experiment

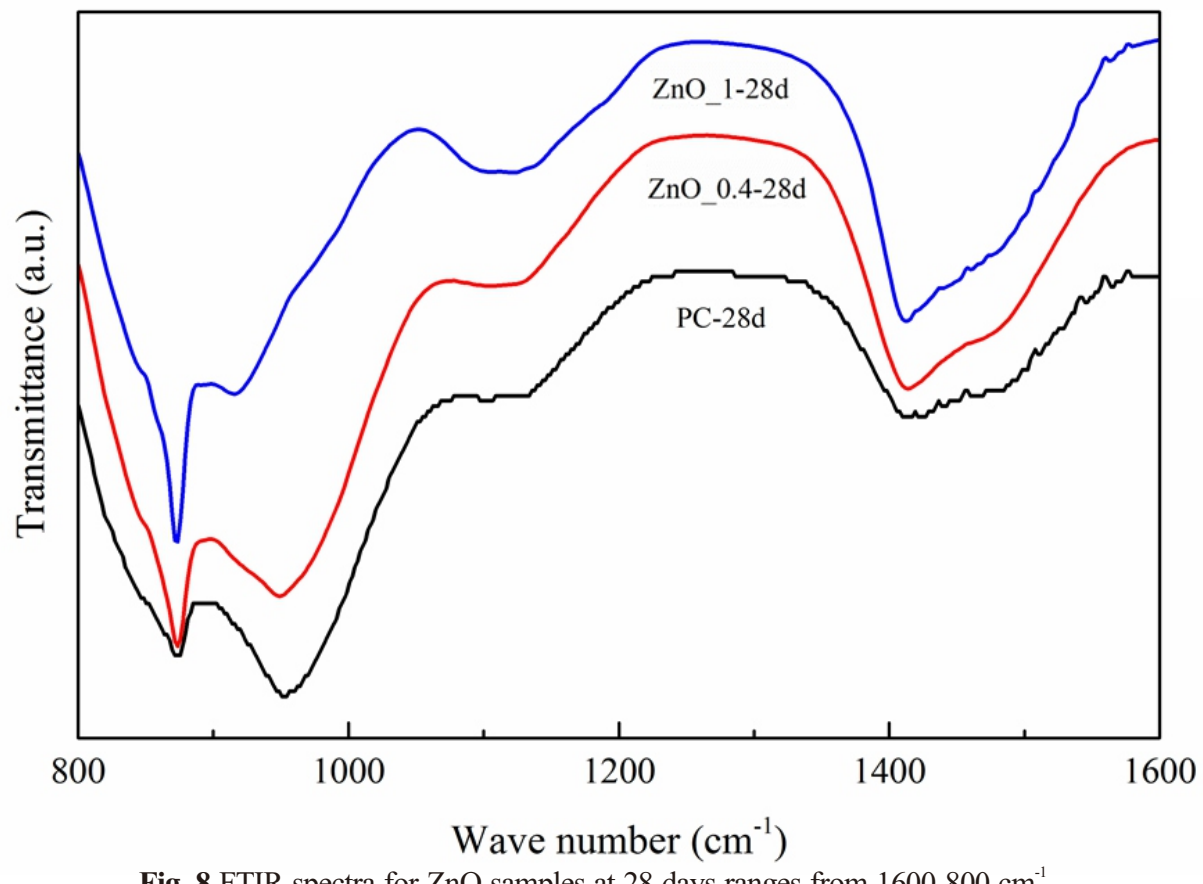

Fig. 8 FTIR spectra for $\mathrm{ZnO}$ samples at 28 days ranges from $1600-800 \mathrm{~cm}^{-1}$

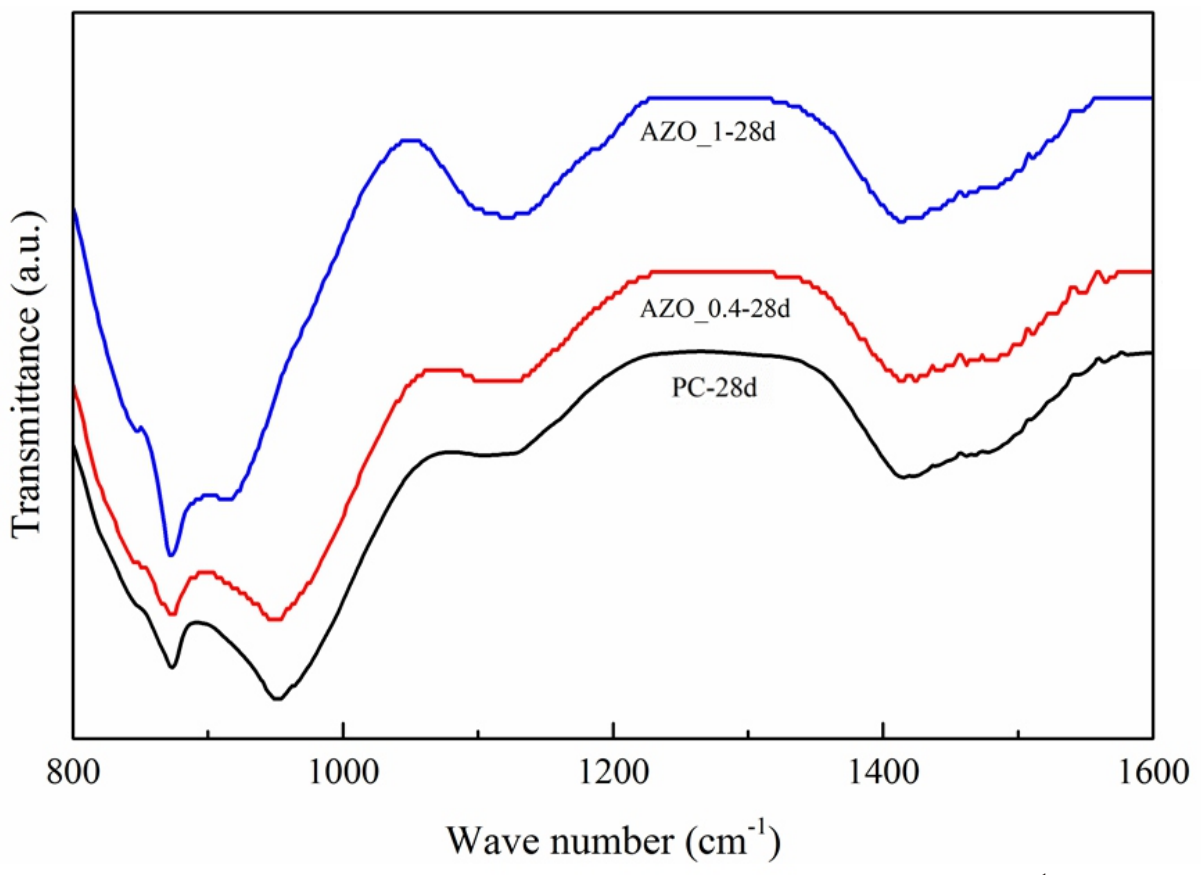

Fig. 9 FTIR spectra for AZO samples at 28 days ranges from $1600-800 \mathrm{~cm}^{-1}$ 
analysis. The degree of hydration (DOH) of $\mathrm{PC}$ was increased $5 \%$ with age. Both $\mathrm{ZnO}$ and AZO mixes showed a decrease in the amount of $\mathrm{DOH}$ while increasing the dosage. The decrease amount is significant at the age of 3 and 7 days. At the age of 28 days, AZO_0.2 and AZO_0.4 showed a slight decrease in the amount of DOH compared with PC, i.e. $6 \%$ and $10 \%$ lower than that of the PC mix, respectively. Due to the fact that AZO nanoparticles have the highest surface area to volume ratio among the common concrete particles, it is preferred to use such nanoparticles in the mixture. They can be considered as filler which then makes ITZ and the microstructure denser.

\subsection{FTIR analysis}

Molecular absorption and transmission can be observed by means of FTIR spectra. The molecular finger prints and IR spectral bands for $\mathrm{ZnO}$ and $\mathrm{AZO}$ are presented in Fig. 8 and Fig. 9, respectively. In some parts of the analysis, possible FTIR peaks from Ylmen et al. were used to match our obtained wave numbers. ${ }^{44}$ For $\mathrm{CO}_{3}$, the related wave number is $1414 \mathrm{~cm}^{-1}, v 3$ for $\mathrm{SO}_{4}$ is $1109 \mathrm{~cm}^{-1}$, and $v 2$ for $\mathrm{CO}_{3}$ is $872 \mathrm{~cm}^{-1}$. In general, the dominant band is $920 \mathrm{~cm}^{-1}$, which is attributed to asymmetric Si-O stretching (v3) out-of-plane Si-O bending (v4) and inplane Si-O bending ( $v 2)$. From $1105 \mathrm{~cm}^{-1}$, the $\mathrm{SO}_{4}^{2-}$ stretching vibration (v3) can be observed. ${ }^{36}$ Also at $1600 \mathrm{~cm}^{-1}$ wide bands of vibration are available. This could be due to the $\mathrm{O}-\mathrm{H}$ vibration of water molecules. ${ }^{45}$ From $1470-1410 \mathrm{~cm}^{-1}$, asymmetric stretching vibration was observed as an indication of $\mathrm{CO}_{3}^{2-}$. At $860 \mathrm{~cm}^{-1}$ weak bands of $\mathrm{CO}_{3}^{2-}$ bending vibration was developed. At $960 \mathrm{~cm}^{-1}$, a considerable high frequency band, $\mathrm{xCaO} \cdot \mathrm{ySiO}_{2} \cdot 2 \mathrm{H}_{2} \mathrm{O}$ is formed. In the range of $1100-1140 \mathrm{~cm}^{-1}$ where sulfate is available, a shift to a weaker band $\left(1114 \mathrm{~cm}^{-1}\right)$ was observed.

$\mathrm{Zn}(\mathrm{OH})_{2}$ is an amorphous compound, therefore, it cannot be determined by XRD analysis. According to the FTIR spectra of AZO_1 wt. $\%$, at the age of 28 days, S-O stretching band has been moved from $1120 \mathrm{~cm}^{-1}$ to $1102 \mathrm{~cm}^{-1}$. Mollah et al., ${ }^{34}$ on the other hand, specified that the $\mathrm{CaZn}_{2}(\mathrm{OH})_{6} \cdot 2 \mathrm{H}_{2} \mathrm{O}$ is considerably lower than that of $\mathrm{CH}$ in terms of quantity, therefore, in XRD analysis it cannot be observed. It is widely known that $\mathrm{Zn}(\mathrm{OH})^{3-}$ are found in high concentration in the porous water. ${ }^{45}$ Such ions will react with $\mathrm{Ca}^{2+}$ ions and $\mathrm{CaZn}_{2}(\mathrm{OH})_{6}$. $2 \mathrm{H}_{2} \mathrm{O}$ is formed. ${ }^{36,46}$ Mollah and Yousuf ${ }^{47}$ realized that $\mathrm{Zn}(\mathrm{OH})_{2}$ which is an amorphous layer causes retardation by covering clinker particles. This will cause further reaction between $\mathrm{Ca}^{2+}$ ions and zinc hydroxide which produces $\mathrm{CaZn}_{2}(\mathrm{OH})_{6} \cdot 2 \mathrm{H}_{2} \mathrm{O}$. And after this step, hydration process will initiate. FTIR spectra of PC, AZO_0.4, and $\mathrm{AZO}_{-} 1$ is presented in Fig. 9. At the age of 28 days, considerable difference between PC FTIR spectra and ZnO FTIR spectra was observed, which shows $\mathrm{ZnO}$ retardation effect (Fig. 8). However, AZO showed slightly similar spectra to $\mathrm{PC}$ which is in agreement with the previous experiments. This shows the fact that AZO could enhance the hydration properties of the cement past compared to that of the cement paste with $\mathrm{ZnO}$, and the results are is in agreement with DSC, TGA, XRD analysis. Therefore, AZO compounds can be used in concrete industry to tailor the hydration process of cement paste.

\section{Conclusions}

In this study, the effect $\mathrm{ZnO}$ nanoparticles and $\mathrm{AZO}$ alloys on the hydration behavior of cement pastes was studied. Results indicated that AZO nanoparticles can improve the hydration properties of cement paste comparing to that of $\mathrm{ZnO}$. When exposed to C-S-H, AZO nanoparticles' covalent-bonding are weakened due to the higher attraction forces from silicon and calcium chain molecules. Therefore, it can provide higher number of locations for nucleation sites for cement particles. It was found that the pastes containing AZO exhibited better performance in terms of the hydration behavior due to the aluminum acceleration shields, containing four and five fold coordinated aluminum sites and an $\mathrm{Al}$ site coordinated to six oxygen atoms. The addition of AZO nanoparticle was found to be effective in reducing the induction period time compared with $\mathrm{ZnO}$ nanoparticle, however, this effect is highly influenced by the amount of AZO in the cement composite in that no distinctive behavior on the time to reach the maximum exothermic peak was observed for samples containing AZO more than 0.4 wt. \%. At higher concentration than 0.6 wt. \%, both AZO and $\mathrm{ZnO}$ nanoparticles led to a significant delay in the hydration process.

$\mathrm{XRD}$ and TGA analysis depict the fact that at early ages, $\mathrm{ZnO}$ nanoparticles cover cement particles leading to a small amount of hydration products. FTIR analysis approves that $\mathrm{ZnO}$ acted as a retarder as a clear formation of $\mathrm{Zn}(\mathrm{OH})_{2}$ and calcium hydrozincate. Retarding action of $\mathrm{Zn} \mathrm{O} 0.2$ led to a reduction in the formation of $\mathrm{C}-\mathrm{S}-\mathrm{H}$ which is lower than that of AZO_0.2. This shows the fact that AZO could enhance the hydration properties of the cement past compared to that of the cement paste with $\mathrm{ZnO}$.

\section{Acknowledgements}

The authors are grateful to Prof. Jan Olek at Purdue University for providing valuable discussion, and the financial supports from National Science Foundation CAREER program (under Grants of CMMI 1560834).

\section{References}

1. E. Ghafari, S. Ghahari, Y. Feng, F. Severgnini and N. Lu, Comp. B: Eng., 2016, 105, 160-166.

2. S. Ghahari, 2016.

3. L. Ahmed Sbia, A. Peyvandi, P. Soroushian, A. M. Balachandra and K. Sobolev, Cons. and Buil. Mater., 2015, 76, 413-422.

4. A. Peyvandi, L. A. Sbia, P. Soroushian and K. Sobolev, Cons. and Buil. Mater., 2013, 48, 265-269.

5. F. J. Ulm, Arab. J. for Sci. and Eng., 2012, 37, 481-488.

6. F. J. Ulm, Poromechanics IV - 4th Biot Conference on Poromechanics, 2009.

7. J. Zhao, L. Wu, C. Zhan, Q. Shao, Z. Guo and L. Zhang, Polymer, 2017.

8. C. Cheng, R. Fan, Y. Ren, T. Ding, L. Qian, J. Guo, X. Li, L. An, Y. Lei and Y. Yin, Nanoscale, 2017, 9, 5779-5787.

9. M. Aly, M. S. J. Hashmi, A. G. Olabi, M. Messeiry, E. F. Abadir and A. I. Hussain, Mater. \& Des., 2012, 33, 127-135.

10. L. Senff, D. M. Tobaldi, P. Lemes-Rachadel, J. A. Labrincha and D. Hotza, Cons. and Buil. Mater, 2014, 65, 191-200.

11. M. h. Zhang and H. Li, Cons. and Buil. Mater. 2011, 25, 608-616.

12. E. Ghafari, M. Arezoumandi, H. Costa and E. Júlio, Cons. and Buil. Mater, 2015, 94, 181-188.

13. T. Tong, Z. Fan, Q. Liu, S. Wang, S. Tan and Q. Yu, Cons. and Buil. Mater, 2016, 106, 102-114.

14. M. Heikal, S. Abd El Aleem and W. M. Morsi, HBRC Journal, 2013, 9, $243-$ 255.

15. G. Kenanakis, D. Vernardou and N. Katsarakis, Appl. Cata. A: General, 2012, 411-412, 7-14.

16. S. A. Khayyat, M. Abaker, A. Umar, M. O. Alkattan, N. D. Alharbi and S. Baskoutas, J. of nanosci. and nanotech., 2012, 12, 8453-8458.

17. N. J. Lowe, Sunscreens: development: evaluation, and regulatory aspects, CRC Press, 1996.

18. D. B. Brown, A. E. Peritz, D. L. Mitchell, S. Chiarello, J. Uitto and F. P. Gasparro, Photochem. and photobio., 2000, 72, 340-344.

19. A. A. Tomchenko, G. P. Harmer, B. T. Marquis and J. W. Allen, Sens. and Actu. B, 2003, 93, 126-134.

20. S. Ghahari, E. Ghafari and N. Lu, Constr. Build. Mater, 2017, 46, 755-763.

21. S. Minne, S. Manalis and C. Quate, App. Phys. Lett., 1995, 67, 3918-3920.

22. Z. Guo, S. Wei, B. Shedd, R. Scaffaro, T. Pereira and H. T. Hahn, J. Mater. 
Chem., 2007, 17, 806-813.

23. F. F. Ataie, M. C. G. Juenger, S. C. Taylor-Lange and K. A. Riding, Cem. and Conc. Res., 2015, 72, 128-136.

24. S. B. Neal and A. C. Michael, Conc. Inter. 2013, 35, $42-46$.

25. K. G. Kolovos, S. Barafaka, G. Kakali and S. Tsivilis, Ceramics- Silikaty, 2005, 49, 205-212.

26. C. Tashiro and J. Oba, Cem. and Conc. Res., 1979, 9, 253-258.

27. F. Puertas, I. García-Díaz, M. Palacios, M. F. Gazulla, M. P. Gómez and M. Orduña, Cem. and Conc. Comp., 2010, 32, 175-186.

28. M. A. Trezza, Mater. Res., 2007, 10, 331-334.

29. A. Stumm, K. Garbev, G. Beuchle, L. Black, P. Stemmermann and R. Nüesch, Cem. and Conc. Res., 2005, 35, 1665-1675.

30. S. C. Taylor-Lange, K. A. Riding and M. C. G. Juenger, Cem. and Conc. Comp., 2012, 34, 835-847.

31. ASTMC150, 2012

32. M. Yousuf, A. Mollah, R. K. Vempati, T. C. Lin and D. L. Cocke, Wast. Mana., 1995, 15, 137-148.

33. M. A. Trezza, Mater. Res., 2007, 10, 331-334.

34. M. Yousuf, A. Mollah, J. Pargat and D. L. Cocke, J. Env. Sci. \& Heal. Part A, 1992, 27, 1503-1519.
35. M. Gawlicki and D. Czamarska, J. ther. anal., 38, 2157-2161.

36. I. F. Olmo, E. Chacon and A. Irabien, Cem. and Conc. Res., 2001, 31, $1213-$ 1219.

37. M. Vaseem, A. Umar and Y. B. Hahn, American Scientific Publishers: New York, 2010, vol. 5, pp. 1-36.

38. Y. S. Avadhut, J. Weber, E. Hammarberg, C. Feldmann and J. Schmedt auf der Gunne, Phys. Chem. Chem. Phy., 2012, 14, 11610-11625.

39. S. Barbhuiya, S. Mukherjee and H. Nikraz, Cons. and Buil. Mater., 2014, 52, 189-193.

40. N. León, J. Massana, F. Alonso, A. Moragues and E. Sánchez-Espinosa, Biosys. Eng., 2014, 123, 1-11.

41. M. H. Rafieipour, A. Nazari, M. A. Mohandesi and G. Khalaj, Mater. Res., 2012, 15, 177-184.

42. R. Ylmén, U. Jäglid, B. M. Steenari and I. Panas, Cem. and Conc. Res., 2009, 39, 433-439.

43. T. Nochaiya, Y. Sekine, S. Choopun and A. Chaipanich, J. Alloys and Comp., 2015, 630, 1-10.

44. M. Gawlicki and D. Czamarska, J. Therm. Anal. Calor., 1992, 38, $2157-$ 2161.

45. M. Y. A. Mollah, F. Lu and D. L. Cocke, Sci. Total. Environ., 1998, 224, $57-$ 68. 